OPEN ACCESS

Edited by:

Olivier Sitbon,

Université Paris-Saclay, France

Reviewed by:

Harm Bogaard

VU University Medical

Center, Netherlands

Aaron Waxman

Brigham and Women's Hospital and

Harvard Medical School,

United States

*Correspondence:

Silvia Ulrich

silvia.ulrich@usz.ch

Specialty section:

This article was submitted to

Pulmonary Medicine,

a section of the journal

Frontiers in Medicine

Received: 14 September 2021

Accepted: 25 October 2021

Published: 23 November 2021

Citation:

Duknic M, Lichtblau M, Saxer S, Berlier C, Schneider SR, Schwarz EI, Carta AF, Furian M, Bloch KE and

Ulrich S (2021) Comparison of

Repetitive Cardiac Output

Measurements at Rest and End-Exercise by Direct Fick Using Pulse Oximetry vs. Blood Gases in

Patients With Pulmonary

Hypertension. Front. Med. 8:776956.

doi: 10.3389/fmed.2021.776956

\section{Comparison of Repetitive Cardiac Output Measurements at Rest and End-Exercise by Direct Fick Using Pulse Oximetry vs. Blood Gases in Patients With Pulmonary Hypertension}

Milos Duknic ${ }^{1,2}$, Mona Lichtblau ${ }^{1,2}$, Stéphanie Saxer ${ }^{1,2}$, Charlotte Berlier ${ }^{1,2}$, Simon R. Schneider ${ }^{1,2}$, Esther I. Schwarz ${ }^{1,2}$, Arcangelo F. Carta ${ }^{1,2}$, Michael Furian ${ }^{1,2}$, Konrad E. Bloch ${ }^{1,2}$ and Silvia Ulrich ${ }^{1,2 *}$

\section{${ }^{1}$ Department of Pulmonology, University Hospital Zürich, Zurich, Switzerland, ${ }^{2}$ University of Zurich, Zurich, Switzerland}

Background: Exact and simultaneous measurements of mean pulmonary artery pressure (mPAP) and cardiac output (CO) are crucial to calculate pulmonary vascular resistance (PVR), which is essential to define pulmonary hypertension $(\mathrm{PH})$. Simultaneous measurements of mPAP and CO are not feasible using the direct Fick (DF) method, due to the necessity to sample blood from the catheter-tip. We evaluated a modified DF method, which allows simultaneous measurement of mPAP and CO without needing repetitive blood samples.

Methods: Twenty-four patients with pulmonary arterial or chronic thromboembolic $\mathrm{PH}$ had repetitive measurements of $\mathrm{CO}$ at rest and end-exercise during three phases of a crossover trial. CO was assessed by the original DF method using oxygen uptake, measured by a metabolic unit, and arterial and mixed venous oxygen saturations from co-oximetry of respective blood gases served as reference. These $\mathrm{CO}$ measurements were then compared with a modified DF method using pulse oximetry at the catheter- and fingertip.

Results: The bias among CO measurements by the two DF methods at rest was -0.26 $\mathrm{L} /$ min with limits of agreement of $\pm 1.66 \mathrm{~L} / \mathrm{min}$. The percentage error was $28.6 \%$. At the end-exercise, the bias between methods was $0.29 \mathrm{~L} /$ min with limits of agreement of $\pm 1.54 \mathrm{~L} / \mathrm{min}$ and percentage error of $16.1 \%$.

Conclusion: Direct Fick using a catheter- and fingertip pulse oximetry (DFp) is a practicable and reliable method for assessing $\mathrm{CO}$ in patients with $\mathrm{PH}$. This method has the advantage of allowing simultaneous measurement of PAP and $\mathrm{CO}$, and frequent repetitive measurements are needed during exercise.

Clinical Trial Registration: https://clinicaltrials.gov/ct2/show/NCT02755259, identifier: NCT02755259.

Keywords: cardiac output, direct Fick, pulse oximetry, exercise, pulmonary hypertension 


\section{INTRODUCTION}

In the absence of relevant lung diseases, the two major forms of precapillary pulmonary hypertension $(\mathrm{PH})$ are pulmonary arterial and chronic thromboembolic pulmonary hypertension (PAH/CTEPH). $\mathrm{PH}$ is a relatively rare condition with potentially drastic limitations in prognosis and quality of life (1-3). PH is diagnosed and hemodynamically classified by right heart catheterization (RHC) as mean pulmonary artery pressure (mPAP) $>20 \mathrm{mmHg}$ with a pulmonary artery wedge pressure (PAWP) $\leq 15 \mathrm{mmHg}$ (3-5). In 2019, it was proposed to include a pulmonary vascular resistance (PVR) of $\geq 3$ WU into the definition of precapillary $\mathrm{PH}$, to increase the specificity of diagnosis (5). To calculate the PVR, simultaneous measurement of cardiac output (CO) and mPAP is necessary (6). Thus, accurate assessment of $\mathrm{CO}$ is crucial for diagnosis, classification, therapeutic decisions, and prognostic evaluation in $\mathrm{PH}(5,7)$. Inaccuracy and imprecision of $\mathrm{CO}$ measurement techniques can lead to misdiagnosis or inadequate treatment decisions. These aspects highlight the relevance of reliable CO measurements at rest, but also during vasoreactivity testing and exercise challenge at the time of diagnosis or during followup of patients with $\mathrm{PH}$ to evaluate effects of therapy and prognosis (8).

Cardiac output can be measured with different methods. The gold standard has been the direct Fick (DF) method, albeit with certain reservations because it requires simultaneous measurement of oxygen consumption and, in its original form, simultaneous arterial and mixed venous blood samples to assess oxygen saturation in the blood by co-oximetry, which limits frequent repetitive assessments (9). Furthermore, mPAP cannot be measured simultaneously when sampling blood from the catheter-tip, which prohibits simultaneous assessments of mPAP, $\mathrm{CO}$, and PAWP to calculate PVR with standard equipment, such as the widely used Swan-Ganz catheter, and thus may limit accurate measurement in non-steady state condition. This challenges accurate hemodynamic measurement in a biologically fluctuating system already at rest but makes the DF method impractical during incremental exercise. Replacing repetitive measurements of arterial and mixed venous oxygen content by continuous assessment of pulse- and catheter-tip oximetry $\left(\mathrm{SpO}_{2}\right.$ and $\left.\mathrm{SpmvO}_{2}\right)$ requires blood gas sampling only once. Additionally, it allows-together with continuous oxygen uptake $\left(\mathrm{VO}_{2}\right)$ registration-continuous $\mathrm{CO}$ assessment. This slightly modified DF method is herein referred to as "DF pulse oximetry" (DFp).

Another widely used method to measure $\mathrm{CO}$ is intermittent pulmonary thermodilution (TD), which does not require equipment to assess $\mathrm{VO}_{2}$ from breathing gases.

The main aim of this study was to evaluate the precision and accuracy of CO measured by DF using a catheter and fingertip pulse oximetry (DFp) in comparison to DF using oxygen saturation derived by co-oximetry from blood gases (DF), at rest and at end-exercise in patients with PH. An additional aim was to compare TD vs. DF at rest and end-exercise.

\section{METHODS}

\section{Study Design and Participants}

This study included patients with PAH/CTEPH diagnosed according to international guidelines from 2015 (3). Patients without $\mathrm{PH}$ or $\mathrm{PH}$ classified to other diagnostic groups were excluded. In all patients, the right heart catheterization (RHC) examination was clinically indicated, and patients provided written informed consent to participate in a prospective randomized, placebo-controlled, double-blinded, triple-phase, and crossover trial evaluating acute hemodynamic effects of acetazolamide at rest and end-exercise. The study design, methods, and results on the acute hemodynamic effect of acetazolamide on PVR and other measures at rest have been published (10). This study focuses on the comparison of the CO at rest and end-exercise measured by different methods, and these results have not been previously published.

The study complies with the declaration of Helsinki and was approved by the local ethics committee (BASEC 2016-00089, and the trial was registered at ClinicalTrials.gov (NCT02755259).

\section{Interventions and Assessments Catheterization and CO Measurements}

The right heart catheterization was performed in the supine position using a balloon-tipped, triple-lumen, fluid-filled 7.5F Swan-Ganz catheter (Swan Ganz CCOmbo V, Edwards Lifesciences, Irvine, CA, USA) inserted into the right or left internal jugular vein under sonographic guidance. Transducers were set at the midthoracic level and zeroed to atmospheric pressure (11). Additionally, A 5F Teflon catheter was inserted into a radial artery. CO using different methods (DF, DFp, and TD) was repetitively assessed at rest and at end-exercise in three phases each 60-90 min apart according to the protocol (10). Resting blood gas was sampled in the supine position, all other measurements were conducted in the semi-supine position.

\section{Exercise and Spirometry}

Patients performed cycling exercise in semi-supine position with 3 min stepwise incremental increase of work-rates by $10-20$ Watts to maximal exhaustion (Thera-vital Ergometer; Medica Medizin $\mathrm{GmbH})$. Oxygen uptake $\left(\mathrm{VO}_{2}\right)$ was measured with a metabolic unit (Ergo-, Spirostik) and BlueCherry (Geratherm Respiratory, Germany) and averaged over 15 seconds.

\section{Blood Gas Analysis and Oximetry}

Arterial and mixed venous blood samples were taken from the radial artery line and the pulmonary artery catheter-tip. The first resting mixed venous blood gas analysis $\left(\mathrm{SmvO}_{2}\right)$ was used to calibrate pulse oximetry at the catheter-tip $\mathrm{SpmvO}_{2}$. Finger- and catheter-tip pulse oximetry $\left(\mathrm{SpO}_{2}\right.$ and $\left.\mathrm{SpmvO}_{2}\right)$ were continuously measured and registered in LabChart (Version 8.1.16; ADInstruments).

To calculate the $\mathrm{CO}$ by the DF methods, we used the following formula: $\mathrm{DF}=\mathrm{VO}_{2}[1 / \mathrm{min}] /\left(\right.$ hemoglobin $[\mathrm{g} / \mathrm{dl}] \times 13.4 \times\left(\mathrm{SaO}_{2}-\right.$ $\left.\left.\mathrm{SmvO}_{2}[\%] / 100\right) \times 1,000\right)(12)$. The DF method using arterialand mixed venous blood gases served as reference for comparison 
with DFp and TD. To calculate DFp, we used in analogy the formula: $\mathrm{DFp}=\mathrm{VO}_{2}[\mathrm{l} / \mathrm{min}] /($ hemoglobin $[\mathrm{g} / \mathrm{dl}] \times 13.4 \times$ $\left.\left(\mathrm{SpO}_{2}-\mathrm{SpmvO}_{2}[\%] / 100\right) \times 1,000\right)$.

\section{Intermittent TD}

Cardiac output by TD was measured in triplicate by cold saline injection (Vigilance II, Edwards Lifesciences, Irvine, CA, USA) $(3,13,14)$. At each time point, two to three measurements were performed. Measurements were excluded if they varied $>10 \%$ from each other, and the mean value was calculated using the remaining measurements.

\section{Outcomes}

The main purpose was the difference in CO between DF based on blood gas analysis and DF based on pulse oximetry at rest and end-exercise. An additional purpose was the difference in $\mathrm{CO}$ between DF and TD at rest and end-exercise.

\section{Statistical Analysis}

Assessed data were inspected visually in the LabChart program for plausibility, and artifacts were deleted. Continuously registered data were averaged over periods of 15 seconds. Where appropriate, i.e., during a steady state, missing data points were carried forward. The results are expressed as means \pm SD unless indicated otherwise. The normality assumption was tested using the Shapiro-Wilk test. Heteroscedasticity was assessed using the studentized Breusch-Pagan test. The agreement and bias were assessed by the method described by Bland and Altman (15). Bias was expressed as the mean of the differences obtained by different techniques (e.g., oDF-DF and TD-DF) with its 95\% CI. The limits of agreement are expressed as mean \pm 1.96 SD. Percentage error was derived by dividing the limits of the agreement by the mean of both methods. The coefficient of variation was obtained by dividing the SD of a method by its respective mean. The repeatability coefficient was calculated according to Carstensen et al. (16) for linked or paired replicates under the assumption of identical conditions. The paired data structure also had an influence on further statistical parameters. All statistical analyses were performed using RStudio (Version 1.2.1578, R Studio Inc., San Francisco, CA, USA). Acceptance criteria were defined as limits of agreement within $2 \mathrm{~L} / \mathrm{min}$ and a percentage error of $30 \%$ (17).

\section{RESULTS}

\section{Patient Characteristics}

We included 24 patients (7 female) with PH (CTEPH, $n=$ 17; $\mathrm{PAH}, n=7)$. Patient characteristics and baseline resting hemodynamics are shown in Table 1 . The mean age was $59 \pm 14$ years, body mass index (BMI) $27.9 \pm 4.6 \mathrm{~kg} / \mathrm{m}^{2}$, heart rate (HR) $75 \pm 11 \mathrm{bpm}$, and mPAP $37 \pm 12 \mathrm{mmHg}$.

\section{DF Using Blood Gases vs. DF Using Pulse Oximetry}

The average $\mathrm{CO}$ of both methods at rest, end-exercise, and both combined, and further statistical parameters are summarized in
TABLE 1 | Baseline characteristics of the study population.

\begin{tabular}{|c|c|c|}
\hline Baseline characteristics & & $\begin{array}{c}\text { Number }(\%) \text { or mean } \pm \\
\text { SD }\end{array}$ \\
\hline No. of patients & & 24 \\
\hline \multirow[t]{2}{*}{$\operatorname{Sex}(\%)$} & Male & $17(71 \%)$ \\
\hline & Female & 7 (29\%) \\
\hline Age, yr & & $59 \pm 14$ \\
\hline BMl, $\mathrm{kg} / \mathrm{m}^{2}$ & & $27.9 \pm 4.6$ \\
\hline \multirow{2}{*}{$\begin{array}{l}\text { Pulmonary hypertension } \\
\text { classification (\%) }\end{array}$} & $\mathrm{PAH}$ & $7(29 \%)$ \\
\hline & CTEPH & $17(71 \%)$ \\
\hline \multirow[t]{4}{*}{ NYHA (\%) } & I & $2(8 \%)$ \\
\hline & $\|$ & $15(63 \%)$ \\
\hline & III & $7(29 \%)$ \\
\hline & IV & $0(0 \%)$ \\
\hline 6-min walk distance, m & & $531 \pm 112$ \\
\hline Body surface area, $\mathrm{m}^{2}$ & & $1.99 \pm 0.19$ \\
\hline $\begin{array}{l}\text { NT-proBNP, ng/L (median } \\
{[\mathrm{IQR}] \text { ) }}\end{array}$ & & $258[82,485]$ \\
\hline Heart rate, bpm & & $75 \pm 11$ \\
\hline $\mathrm{SpO}_{2}, \%$ (median [IQR]) & & $93[91,95]$ \\
\hline $\mathrm{SmvO}_{2}, \%$ (median [IQR]) & & $63[60,67]$ \\
\hline $\begin{array}{l}\text { Mean pulmonary artery } \\
\text { pressure, } \mathrm{mmHg}\end{array}$ & & $37 \pm 11$ \\
\hline $\begin{array}{l}\text { Pulmonary artery wedge } \\
\text { pressure, } \mathrm{mmHg}\end{array}$ & & $11 \pm 2$ \\
\hline $\begin{array}{l}\text { Pulmonary vascular } \\
\text { resistance, WU }\end{array}$ & & $5.2 \pm 2.7$ \\
\hline $\begin{array}{l}\text { Mean systemic blood } \\
\text { pressure, } \mathrm{mmHg}\end{array}$ & & $94 \pm 9$ \\
\hline Right atrial pressure, $\mathrm{mmHg}$ & & $6 \pm 3$ \\
\hline
\end{tabular}

Data are presented as mean $\pm S D$ unless indicated otherwise. BMI, Body mass index; $P A H$, pulmonary arterial hypertension; CTEPH, chronic thromboembolic pulmonary hypertension; NYHA, New York Heart Association (score); NT-proBNP, N-terminal pro b-type Natriuretic Peptide; WU, Woods units.

Table 2. The regression equation including data at rest and endexercise had a slope of 1.07 with an intercept of $-0.50 \mathrm{~L} / \mathrm{min}$ and an $\mathrm{R}^{2}$ of 0.92 (Figure 1A). The normality assumption was met $(p=0.64)$.

Resting values: The distribution of $\mathrm{CO}$ values is illustrated in Figure 2A. Bland-Altman analysis showed a bias of $-0.26 \mathrm{~L} / \mathrm{min}$ (95\% CI, -0.62 to $0.09 \mathrm{~L} / \mathrm{min}$ ) and lower and upper limits of agreement of -1.92 and $1.39 \mathrm{~L} / \mathrm{min}$, respectively (Figure 3A). The percentage error was $28.6 \%$. The coefficient of variation and the repeatability coefficient were $25.3 \%$ and $2.03 \mathrm{~L}$ for DF, respectively, $25.9 \%$ and $<0.01 \mathrm{~L}$ for DFp.

End-exercise values: The distribution of $\mathrm{CO}$ values is illustrated in Figure 2B. The bias was $0.29 \mathrm{~L} / \mathrm{min}(95 \% \mathrm{CI}$, -0.08 to $0.67 \mathrm{~L} / \mathrm{min}$ ). Likewise, the limits of agreement showed no drastic changes, with the lower limit at -1.25 $\mathrm{L} / \mathrm{min}$ and the upper limit at $1.83 \mathrm{~L} / \mathrm{min}$ (Figure 3B). The percentage error decreased to $16.1 \%$. Compared to rest measurements, the coefficient of variation was increased marginally while the repeatability coefficient 
TABLE 2 | Mean cardiac output (CO) and statistical parameters at rest, end-exercise, and both combined.

\begin{tabular}{|c|c|c|c|}
\hline Cardiac output & Rest & End-exercise & Combined rest and end-exercise \\
\hline Maximal workload, W & & $80 \pm 37$ & \\
\hline CO direct Fick blood gases, L/min & $5.9 \pm 1.5$ & $9.4 \pm 2.6$ & $7.5 \pm 2.7$ \\
\hline No. of measurements & 49 & 42 & 91 \\
\hline $\mathrm{CO}$ direct Fick pulse oximetry, L/min & $5.5 \pm 1.5$ & $10.0 \pm 3.2$ & $7.5 \pm 3.3$ \\
\hline No. of measurements & 66 & 51 & 117 \\
\hline CO thermodilution, L/min & $5.5 \pm 1.2$ & $10.7 \pm 3.0$ & $7.3 \pm 3.4$ \\
\hline No. of measurements & 64 & 50 & 114 \\
\hline \multicolumn{4}{|c|}{ Statistical parameters comparing cardiac output measures by direct Fick using blood gases vs. direct Fick using pulseoximetry } \\
\hline Bias (95\% Cl), L/min & $-0.26(-0.62$ to 0.09$)$ & $0.29(-0.08$ to 0.67$)$ & $0.01(-0.35$ to 0.37$)$ \\
\hline Limits of agreement, L/min & -1.92 to 1.39 & -1.25 to 1.83 & -1.67 to 1.69 \\
\hline Percentage error, \% & 28.6 & 16.1 & 22.3 \\
\hline Coefficient of variation (DF/DFp), \% & $25.3^{\star} / 25.9$ & $27.3^{*} / 29.6$ & $36.0 / 39.9$ \\
\hline Repeatability coefficient (DF/DFp), L/min & $2.03 /<0.01$ & $0.99 / 1.72$ & $0.01 / 2.71$ \\
\hline \multicolumn{4}{|c|}{ Statistical parameters comparing cardiac output measures by direct Fick vs. intermittent thermodilution } \\
\hline Bias $(95 \% \mathrm{Cl}), \mathrm{L} / \mathrm{min}$ & $0.45(-0.98$ to 0.08$)$ & 1.39 (0.37 to 2.42) & $0.36(-0.42$ to 1.13$)$ \\
\hline Limits of agreement, L/min & -2.93 to 2.03 & -2.84 to 5.62 & -3.28 to 4.00 \\
\hline Percentage error, \% & 44.6 & 41.6 & 47.2 \\
\hline Coefficient of variation (DF/TD), \% & $24.7^{\star} / 19.8$ & $26.1^{\star} / 26.8$ & $36.2 / 43.7$ \\
\hline Repeatability coefficient (DF/TD), L/min & $2.95 / 1.50$ & $2.72 / 1.86$ & $0.01 / 4.33$ \\
\hline
\end{tabular}

Data are presented as mean $\pm S D$ unless indicated otherwise. W: Watts; DF: direct Fick using arterial and mixed-venous blood gases; DFp, direct Fick using finger- and cathetertip pulseoximetry; TD, thermodilution. "The coefficients of variation for DF vs. DFp and vs. TD do not match, because measurements were included as pairs (i.e., if a TD measurement was not available the corresponding DF measurement was not included and vice versa).

was completely inversed, being $0.99 \mathrm{~L}$ for $\mathrm{DF}$ and $1.72 \mathrm{~L}$ for DFp.

Resting and end-exercise values: Including both resting and end-exercise measurements, the bias showed no noteworthy change $[0.01 \mathrm{~L} / \mathrm{min} \quad(95 \% \mathrm{CI}, \quad-0.35$ to 0.37 $\mathrm{L} / \mathrm{min})$ ]. Similarly, limits of the agreement remained comparable $(-1.67$ to $1.69 \mathrm{~L} / \mathrm{min})$. The percentage error was $22.3 \%$, which equals a decrease of $6.3 \%$ compared to the resting value.

\section{DF Using Blood Gas vs. Intermittent TD}

The average COs of both methods at rest, end-exercise, and both combined, and further statistical parameters are summarized in Table 2. The regression equation for TD and DF, i.e., rest and end-exercise, had a slope of 1.07 with an intercept of $-0.20 \mathrm{~L} / \mathrm{min}$ and an $\mathrm{R}^{2}$ of 0.72 (Figure 1B). However, neither normality $(p<$ $0.05)$ nor homoscedasticity $(p<0.05)$ were met.

Resting values: The distribution of $\mathrm{CO}$ values is illustrated in Figure 2C. The bias was $-0.45 \mathrm{~L} / \mathrm{min}$ ( $95 \% \mathrm{CI},-0.98$ to 0.08 $\mathrm{L} / \mathrm{min}$ ). The limits of agreement were -2.93 and $2.03 \mathrm{~L} / \mathrm{min}$, respectively (Figure 4A). The percentage error was $44.6 \%$, which equals an increase of $16.0 \%$ compared to DF vs. DFp. The coefficient of variation and the repeatability coefficient for TD were lower than that for DF.

Exercise values: The distribution of $\mathrm{CO}$ values is illustrated in Figure 2D. A bias significantly different from zero was detected with $1.39 \mathrm{~L} / \mathrm{min}(95 \% \mathrm{CI}, 0.37-2.42 \mathrm{~L} / \mathrm{min}$. The lower and upper limits of agreement were -2.84 and $5.62 \mathrm{~L} / \mathrm{min}$, respectively (Figure 4B). The percentage error was $41.6 \%$, which equals a decrease of $3.0 \%$ compared to resting measurements. The coefficient of variation and the coefficient of repeatability were increased and were comparable to that of DF.

Resting and exercise values: Including both rest and endexercise, the bias was $0.36 \mathrm{~L} / \mathrm{min}(95 \% \mathrm{CI},-0.42$ to $1.13 \mathrm{~L} / \mathrm{min})$. The limits of agreement were -3.28 and $4.00 \mathrm{~L} / \mathrm{min}$, respectively. The percentage error was $47.2 \%$. Both, the coefficient of variation and the repeatability coefficient were increased more in relation to their counterparts of DF.

\section{DISCUSSION}

In this first study, comparing a modified DFp to the DF using arterial and mixed-venous blood gases, we found that the accuracy and precision to measure the $\mathrm{CO}$ by the modified DFp were within acceptable boundaries over a wide range of $\mathrm{CO}$ values. These results are of high interest, as simultaneous assessments of mPAP and CO are not possible when blood gases have to be sampled from the pulmonary artery through the RHC line, which limits PVR assessments during biologically unstable conditions such as exercise (18-20). The accuracy and precision to assess the CO by TD vs. the DF revealed lower agreements, which may limit its use, especially during incremental exercise.

Percentage error and limits of the agreement should be defined a priori, in the clinical context, and reported with repeatability assessments (21-23). Nevertheless, most comparison studies fail to report those statistical parameters and objective cut-offs for patients with $\mathrm{PH}$ are not established (24). Rather those studies quote the $30 \%$ percentage error as cut-off, as suggested by 

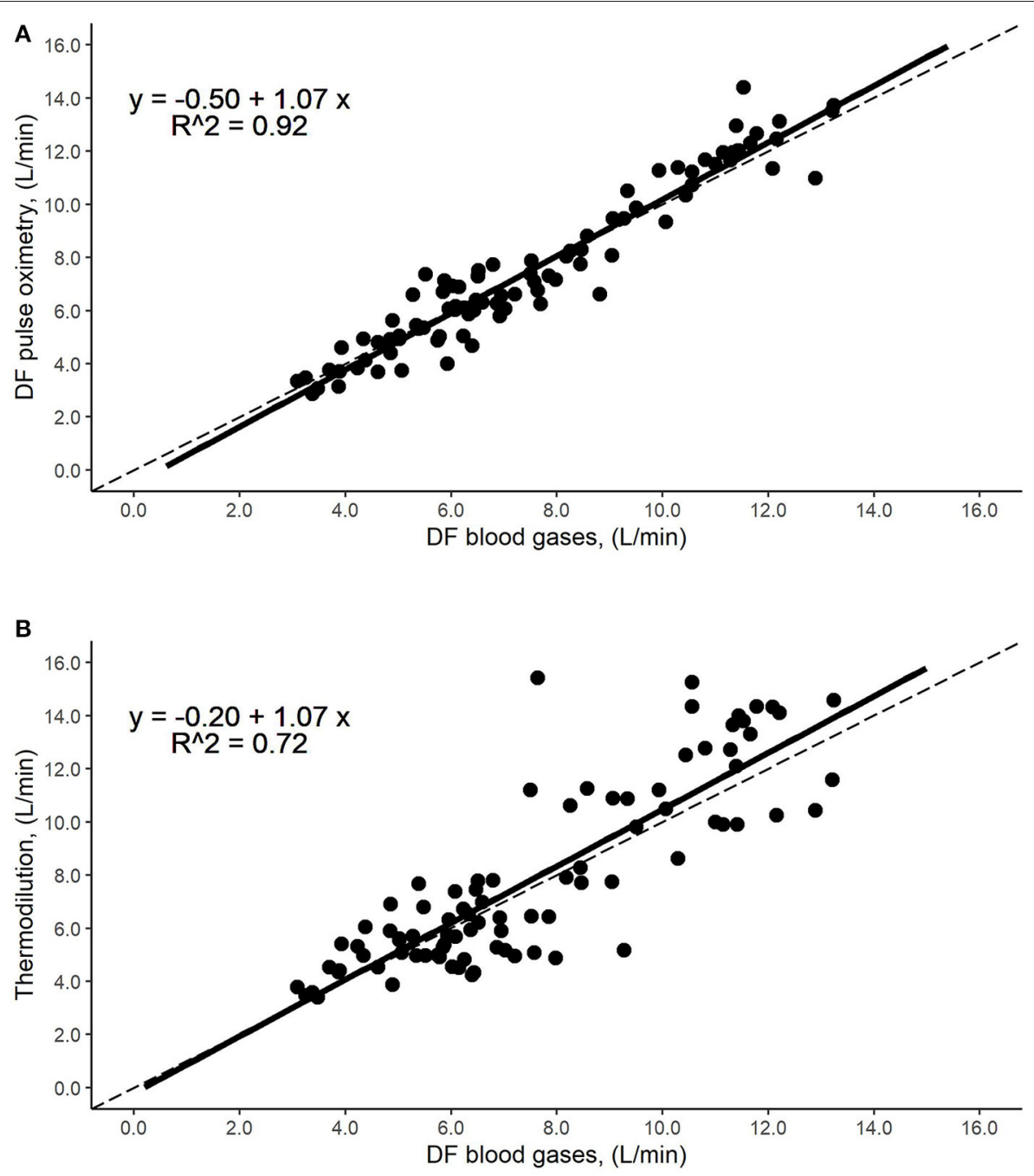

FIGURE 1 | Identity plot of cardiac output (CO) measurement methods. Relationship by regression, such as data points from rest and end-exercise; the dashed line represents the line of equality. The black solid line represents the regression line, while the dots stand for the corresponding measurements. (A) Direct Fick using pulse oximetry (DFp) vs. direct Fick using blood gases (DF): The regression line shows an $R^{2}$ of 0.92 , a slope of 1.07 with an intercept of $-0.50 \mathrm{~L} / \mathrm{min}$ and no displacement over the line of identity over a broad range of CO values. (B) Intermittent thermodilution (TD) vs. direct Fick using blood gases (DF): The regression line shows an $R^{2}$ of 0.72 , a slope of 1.07 with an intercept of $-0.20 \mathrm{~L} / \mathrm{min}$ and no displacement over the line of identity over a broad range of $\mathrm{CO}$ values.

Critchley and Critchley (17) assessing TD vs. DF. In this work, we studied the accuracy and precision of CO assessment using DFp and put it into context to our predefined acceptance criteria over a wide range of values, which were obtained at rest and end-exercise in patients with $\mathrm{PH}$. Thus, our acceptance criteria were based on clinical experience and the wide range of $\mathrm{CO}$ levels. In a review of $\mathrm{CO}$ comparison studies in patients with $\mathrm{PH}$, the acceptance criteria were limits of agreement of \pm 1 $\mathrm{L} / \mathrm{min}$ and a percentage error of $20 \%$. However, those cut-offs were based on critical care and anesthesiology medicine, because studies on patients with $\mathrm{PH}$ were lacking (24). Since there is no established cut-off for the percentage error, we compared it to the widely used $30 \%$ limits mentioned above. In addition, we report the coefficient of variation and repeatability coefficient to allow correct interpretation of the Bland-Altman plot (21, 25). The coefficient of variation describes the contribution of a method to the overall agreement and precision of the two methods. A reference method with a higher coefficient of variation makes an interpretation of the Bland-Altman plot unreasonable (22). The repeatability coefficient is another statistical parameter, which helps to understand the contribution of a method to the lack of agreement (26). It reflects the variation in repeated measurements of the same method. However, it requires repeated measurements or "linked replicates" (16) to be taken into account, which a minority of CO comparison studies reports (24). 

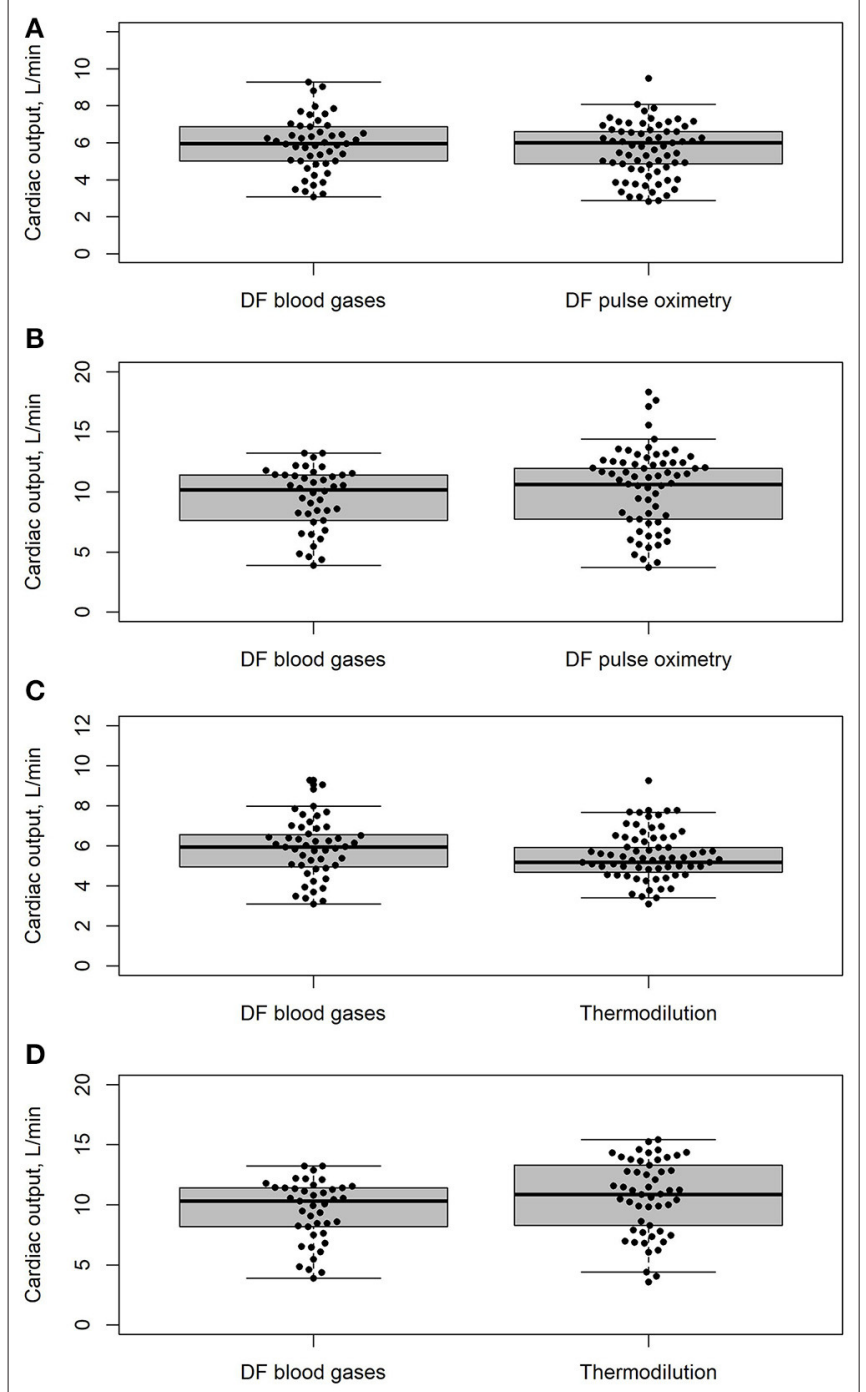

FIGURE 2 | Distribution of cardiac output (CO) measurements by different measurement methods at rest and end-exercise are shown as boxplots. The horizontal line represents the median, the box the 25th to 75th percentile, the whiskers 5th to 95th percentile, and the dots represent the individual values, including outliers. (A) $\mathrm{CO}$ measurement at rest: direct Fick using pulse oximetry (DFp) vs. direct Fick using blood gases (DF)* (B) CO measurements at end-exercise: direct Fick using pulse oximetry (DFp) vs. direct Fick using blood gases $(\mathrm{DF})^{\star}$. (C) $\mathrm{CO}$ measurements at rest: intermittent thermodilution (TD) vs. direct Fick using blood gases (DF)*. (D) CO-measurements at end-exercise: intermittent thermodilution (TD) vs. direct Fick using blood gases (DF)*. *if the corresponding CO measurement was not available or missing, both measurements were excluded.

\section{DF Using Blood Gases vs. DF Using Pulse Oximetry}

Our comparison between the DF and DFp methods showed no displacement of the regression line over the line of identity (Figure 1A), and the mean of the differences was not significantly different from zero (Figures 3A,B), which indicates that adequate accuracy/bias of DF is compared to DFp. Also, the percentage error and the limits of agreement were within predefined acceptance criteria of $30 \%$ and $2 \mathrm{~L} / \mathrm{min}$ (Table 2 ).

At the end-exercise, the percentage error between DFp and DF was decreased drastically while the absolute limits of the agreement remained the same (Table 2), reflecting an even better precision for the DFp method under more strenuous work and therefore higher $\mathrm{CO}$ values. These end-exercise results may even better reflect the precision of DFp to DF, as in our study, setting arterial and mixed venous blood gases were sampled in the supine resting position, whereas $\mathrm{VO}_{2}$ was obtained starting 10-15 min after the patient was set in a stable semi-supine position. This might have influenced the limits of agreement between those two methods at rest. However, this time lag was inevitable to avoid too many blood samples.

Overall, the bias, limits of agreement, and percentage error between CO measurements by DFp and DF were within an acceptable range at rest and good at end-exercise measurements. The coefficient of variation remained approximately the same at rest, end-exercise, and both combined, with the reference method (DF) always showed a smaller value and allowed a rational conclusion of the Bland-Altman plot (22). It suggests that both methods contributed almost equally to agreement/precision in the comparison. Potential oximetry pitfalls, such as hypoperfusion, shivering, or movement artifacts during exercise, cannot be excluded having influenced the coefficient of variation $(27,28)$. The course of the repeatability coefficient and coefficient of variation were found slightly discordant, and the coefficient of repeatability varied during exercise. This may be explained by the crossover study design and our assumptions of interchangeability of the replicates between the three phases and the resulting long pauses between them. The $\mathrm{DF}$ as a gold standard method to assess $\mathrm{CO}$ requires simultaneous blood samples from an artery and the catheter-tip, which requires trained staff that should handle the samples without delay under avoidance of air admixture. Given the fact that DFp does not have these drawbacks and allows for a simultaneous mPAP and therefore pressure/flow measurement, it is a promising alternative to DF and maybe even less prone to errors in case of repetitive assessments during exercise (24). Studies compared other non-invasive methods for CO measurements, such as impedance cardiography to DF, which showed acceptable agreement and precision compared to DF or TD in patients with $\mathrm{PH}$ within a CO range of 3-7 L/min $(29,30)$. Further studies focused on the indirect Fick method to assess CO, which does not measure $\mathrm{VO}_{2}$ but assumes it from nomograms (31). These studies concluded that the LaFarge method was the most precise, but the indirect Fick method was associated with large errors and cannot be recommended $(3,32-36)$. However, those nomograms are not intended for exercise protocols and would possibly be associated with misdiagnosis of $\mathrm{PH}$.

\section{DF Using Blood Gas vs. Intermittent TD}

Thermodilution requires repetitive similar injections of cold saline, which needs time and precludes simultaneous measurement with MPAP, which may introduce bias to pressure/flow measurements in a biologically variable system, 

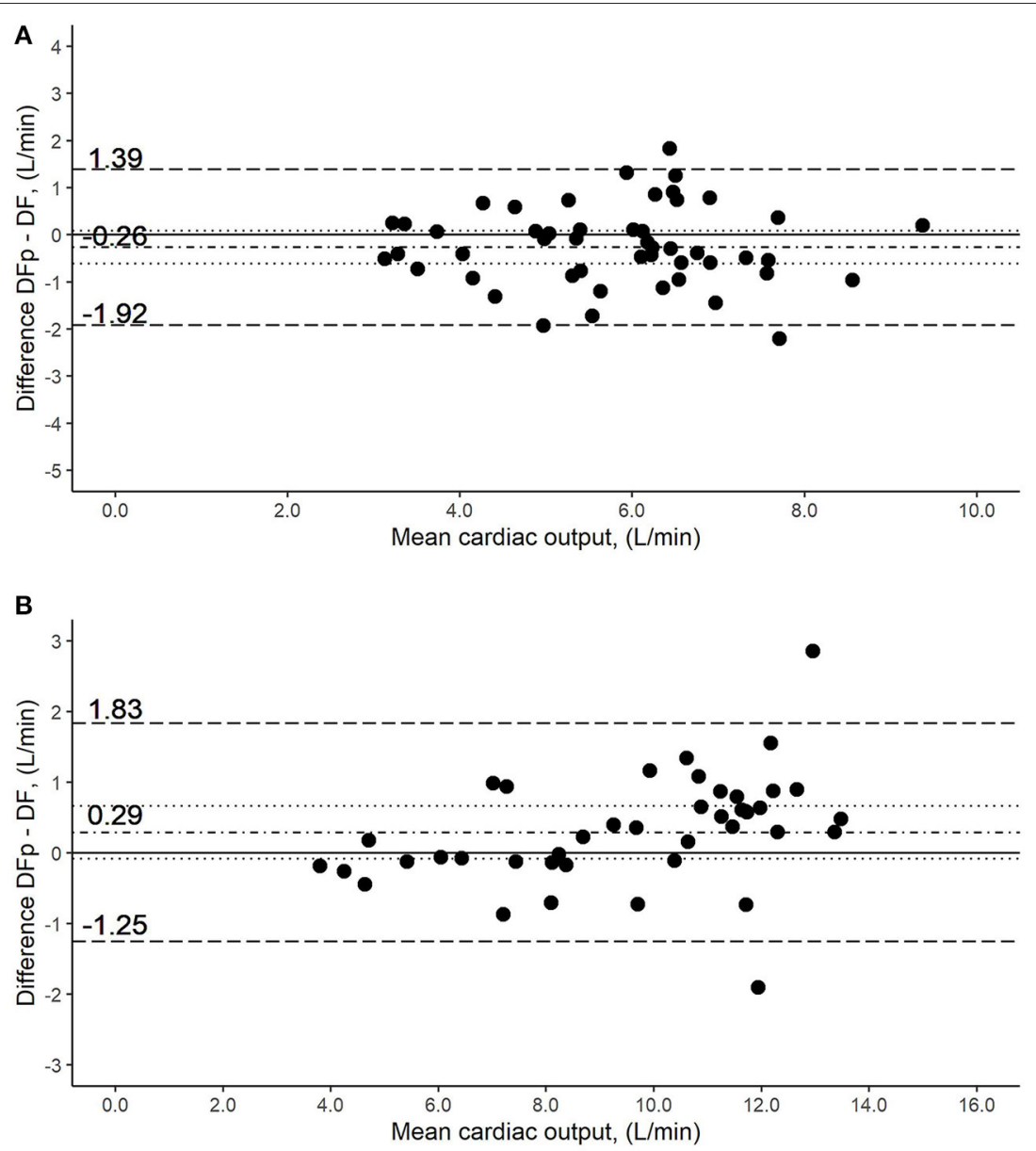

FIGURE 3 | Bland-Altman plot of the comparison of cardiac output (CO) measurement methods by direct Fick using pulse oximetry (DFp) vs. direct Fick using blood gases (DF). Y-axis was calculated as the mean of the two methods being compared. The solid line represents no difference in the means by the two methods. The dot-dashed line around zero represents the measured difference of the means, while the dotted lines stand for the $95 \% \mathrm{Cl}$. The broken lines above and under it, represent the limits of agreements. (A) Measurements at rest: the difference in the means (bias) was $-0.26 \mathrm{~L} / \mathrm{min}(95 \% \mathrm{Cl},-0.62 \mathrm{to} 0.09 \mathrm{~L} / \mathrm{min})$, with the lower and upper limits of the agreement being -1.92 and $1.39 \mathrm{~L} / \mathrm{min}$, respectively. (B) Measurements at end-exercise: bias was $0.29 \mathrm{~L} / \mathrm{min}(95 \% \mathrm{Cl},-0.08 \mathrm{to} 0.67 \mathrm{~L} / \mathrm{min})$, with the lower and upper limits of the agreement being -1.25 and $1.83 \mathrm{~L} / \mathrm{min}$, respectively.

especially during exercise (37-39). Additionally, in comparison to $\mathrm{DF}, \mathrm{TD}$ is more imprecise for lower $\mathrm{CO}$ values and when valvular regurgitation is present $(40)$ - conditions that are frequent in patients with $\mathrm{PH}(9,41)$. As simultaneous assessments are challenging, there have been only a few reports on the agreement between TD and DF in patients with $\mathrm{PH}$, (36) especially during exercise.

The additionally performed CO measurement by intermittent TD did not reveal an acceptable overall agreement with DF during high CO levels, as obtained at the end-exercise. Neither limits of the agreement nor percentage errors were within predefined criteria (Table 2, Figures 4A,B). Although the present study revealed that the limits of agreement between TD and DF were relatively wide at rest, the regression line and its confidence interval showed no displacement above the line of identity over a broad range of $\mathrm{CO}$ values (Figure 1B).
Furthermore, the coefficient of variation was lower than that of the reference method at rest, which renders the rational interpretation of the Bland-Altman plot questionable. A potential explanation for the discrepancies in precision and accuracy would include the response time of the measurement technique, which is aggravated by the time needed for triplicate cold saline injection. Additionally, the limitation of time lag as discussed in the comparison of DFp to DF may also have influenced the measurements.

Measurement of $\mathrm{CO}$ is even more challenging during stepwise incremental exercise, where steps are suggested to be at least $3 \mathrm{~min}$ to reach a steady state (42). Our study shows that agreement of TD to DF is lower at end-exercise than at rest, suggesting a systematic error at high $\mathrm{CO}$ values (43). Additionally, this finding indicates that patients with $\mathrm{PH}$ presumably need more than $3 \mathrm{~min}$ to reach a steady state. This 


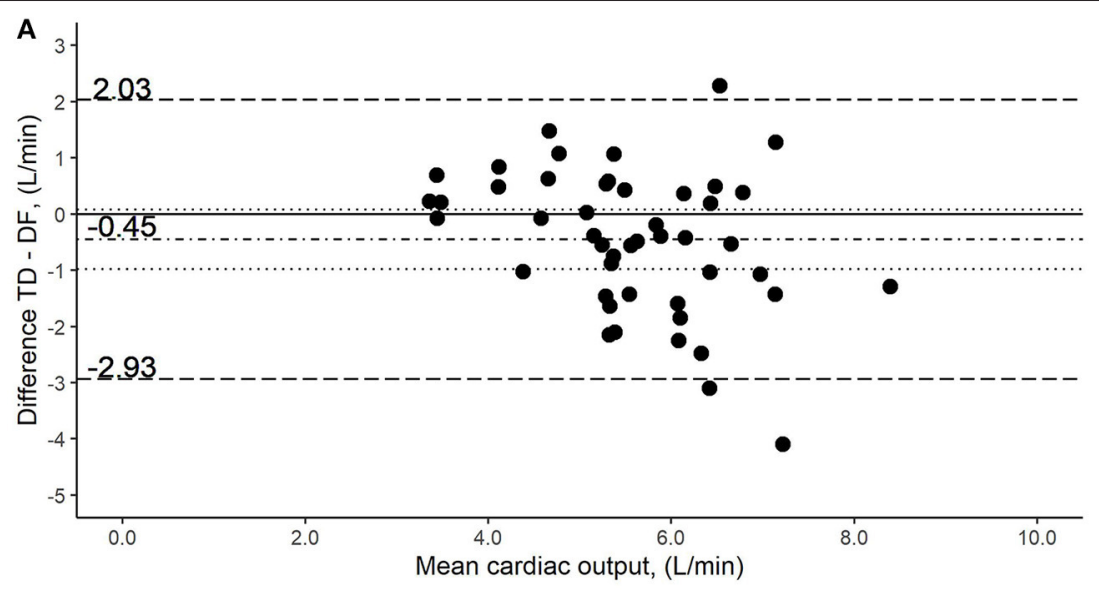

B

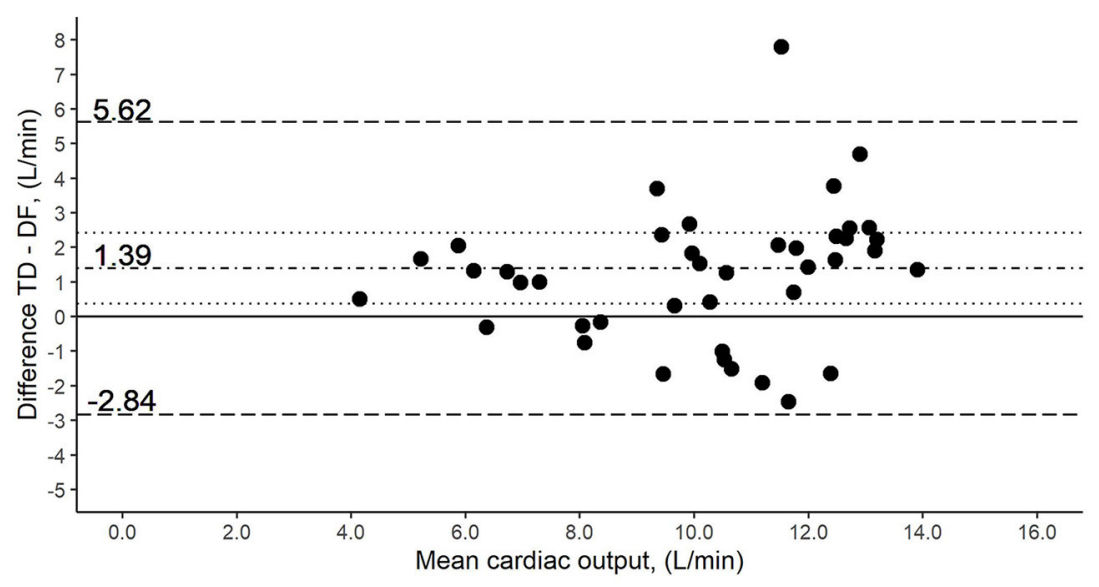

FIGURE 4 | Bland-Altman plot of the comparison of cardiac output (CO) measurement methods by intermittent thermodilution (TD) vs. direct Fick using blood gases (DF). Y-axis was calculated as the mean of the two methods being compared. The solid line represents no difference in the means by the two methods. The dot-dashed line around zero represents the measured difference of the means, while the dotted lines stand for the $95 \% \mathrm{Cl}$. The broken lines above and under it, represent the limits of agreements. (A) Measurements at rest: the difference in the means (bias) was $-0.45 \mathrm{~L} / \mathrm{min}(95 \% \mathrm{Cl},-0.98$ to $0.08 \mathrm{~L} / \mathrm{min})$, with the lower and upper limits of the agreement being -2.93 and $2.03 \mathrm{~L} / \mathrm{min}$, respectively. (B) Measurements at end-exercise: bias was $1.39 \mathrm{~L} / \mathrm{min}(95 \% \mathrm{Cl}, 0.37-2.42 \mathrm{~L} / \mathrm{min})$, with the lower and upper limits of the agreement being -2.84 and $5.62 \mathrm{~L} / \mathrm{min}$, respectively.

would support the findings of Lador et al., who investigated "CO kinetics at the onset of exercise in patients with $\mathrm{PH}$ " and observed that up to $5 \mathrm{~min}$ are warranted to reach a steady state (44). Another study showed that mPAP/CO slopes calculated from $\mathrm{CO}$ by $\mathrm{TD}$ lead to significant overdiagnosis of exercise $\mathrm{PH}$ compared to $\mathrm{CO}$ measured by DF, (45) potentially related to exercise-induced right-to-left shunting, which is commonly found in patients with $\mathrm{PH}$ (46). However, in the present study, $\mathrm{CO}$ was rather overestimated by TD compared to DF at endexercise (Figure 4B). Our and other studies' results thus suggest that accuracy and precision of the $\mathrm{CO}$ measurement during stepwise incremental exercise protocols by the TD method compared to the DF method is lower and thus particularly absolute $\mathrm{CO}$ values measured by this method must be interpreted with caution and in the context of clinical practice and research (47).

\section{LIMITATIONS}

This study used repetitive $\mathrm{CO}$ measurements at rest and endexercise obtained in the context of a randomized-controlled crossover trial studying the acute effect of acetazolamide in $\mathrm{PH}$ and was not specifically designed to compare CO measurements between DF, DFp, and TD, which may have influenced agreement and reproducibility in our setting. To assess the repeatability coefficient more precisely, we would suggest a study design with less time in-between the replicate measurements, because CO is biologically highly variable, reacting to slight changes of physical or emotional stress, body position, and other factors. We also did not compare the $\mathrm{CO}$ on different exercise levels between rest and end-exercise, as we did not draw arterial- and mixed venous blood at each exercise step judging repetitive blood sampling as unacceptable for patients. 


\section{CONCLUSION}

High-frequency repetitive $\mathrm{CO}$ measurements at rest and during stepwise incremental exercise by the modified DFp, using pulse oximetry at the catheter- and fingertip, reveal acceptable agreement with the golden standard DF over a broad range of $\mathrm{CO}$ values in patients with $\mathrm{PH}$. Thus, this modified DFp method maybe a practicable method to assess CO simultaneously with the mPAP, especially during exercise, using everyday equipment, such as the Swan-Ganz catheter.

\section{DATA AVAILABILITY STATEMENT}

The raw data supporting the conclusions of this article will be made available by the authors, without undue reservation.

\section{REFERENCES}

1. Cenedese E, Speich R, Dorschner L, Ulrich S, Maggiorini M, Jenni R, et al. Measurement of quality of life in pulmonary hypertension and its significance. Eur Respir J. (2006) 28:808-15. doi: 10.1183/09031936.06.001 30405

2. Cima K, Twiss J, Speich R, McKenna SP, Grünig E, Kähler CM, et al. The german adaptation of the cambridge pulmonary hypertension outcome review (CAMPHOR). Health Qual Life Outc. (2012) 10:110. doi: 10.1186/1477-7525-10-110

3. Galie N, Humbert M, Vachiery JL, Gibbs S, Lang I, Torbicki A, et al. 2015 ESC/ERS guidelines for the diagnosis and treatment of pulmonary hypertension: the joint task force for the diagnosis and treatment of pulmonary hypertension of the European Society of Cardiology (ESC) and the European Respiratory Society (ERS): endorsed by: association for european paediatric and congenital cardiology (AEPC), international society for heart and lung transplantation (ISHLT). Eur Respir J. (2015) 46:90375. doi: 10.1183/13993003.01032-2015

4. Kovacs G, Berghold A, Scheidl S, Olschewski H. Pulmonary arterial pressure during rest and exercise in healthy subjects: a systematic review. Eur Respir J. (2009) 34:888-94. doi: 10.1183/09031936.00145608

5. Simonneau G, Montani D, Celermajer DS, Denton CP, Gatzoulis MA, Krowka M, et al. Haemodynamic definitions and updated clinical classification of pulmonary hypertension. Eur Respir J. (2019) 53:1801913. doi: 10.1183/13993003.01913-2018

6. Herve P, Lau EM, Sitbon O, Savale L, Montani D, Godinas L, et al. Criteria for diagnosis of exercise pulmonary hypertension. Eur Respir J. (2015) 46:72837. doi: 10.1183/09031936.00021915

7. Hasler ED, Müller-Mottet S, Furian M, Saxer S, Huber LC, Maggiorini M, et al. Pressure-flow during exercise catheterization predicts survival in pulmonary hypertension. Chest. (2016) 150:57-67. doi: 10.1016/j.chest.2016.02.634

8. Faure M, Valentin S, Zysman M, Sitbon O, Peretti L, Guillaumot A, et al. Exercise hemodynamics in the prognosis of patients with pulmonary arterial hypertension. Respir Int Rev Thor Dis. (2020) 99:67885. doi: 10.1159/000509144

9. Hoeper MM, Maier R, Tongers J, Niedermeyer J, Hohlfeld JM, Hamm M, et al. Determination of cardiac output by the Fick method, thermodilution, and acetylene rebreathing in pulmonary hypertension. Am J Respir Crit Care Med. (1999) 160:535-41. doi: 10.1164/ajrccm.160.2.9811062

10. Lichtblau M, Berlier C, Saxer S, Carta AF, Mayer L, Groth A, et al. Acute hemodynamic effect of acetazolamide in patients with pulmonary hypertension whilst breathing normoxic and hypoxic gas: a randomized cross-over trial. Front Med. (2021) 8:681473. doi: 10.3389/fmed.2021.681473

\section{ETHICS STATEMENT}

The studies involving human participants were reviewed and approved by Kantonale Ethikkomission Zürich. The patients/participants provided their written informed consent to participate in this study.

\section{AUTHOR CONTRIBUTIONS}

SU is the guarantor of the paper. All authors meet criteria for authorship as recommended by the International Committee of Medical Journal Editors and contributed to the production of the final manuscript with revision for important intellectual content.

\section{FUNDING}

This study was supported by the Swiss National Science Foundation (No. 32003B_146246/1) and Zurich lung.

11. Kovacs G, Avian A, Olschewski A, Olschewski H. Zero reference level for right heart catheterisation. Eur Respir J. (2013) 42:158694. doi: 10.1183/09031936.00050713

12. Fritts HW, Cournand A. The application of the fick principle to the measurement of pulmonary blood flow. Proc Natl Acad Sci U S A. (1958) 44:1079-87. doi: 10.1073/pnas.44.10.1079

13. Headley JM. Invasive hemodynamic monitoring: applying advanced technologies. Crit Care Nurs Q. (1998) 21:73-84. doi: 10.1097/00002727-199821030-00008

14. Ganz W, Swan HJ. Measurement of blood flow by thermodilution. Am J Cardiol. (1972) 29:241-6. doi: 10.1016/0002-9149(72)90635-2

15. Bland JM, Altman DG. Agreement between methods of measurement with multiple observations per individual. J Biopharm Stat. (2007) 17:57182. doi: 10.1080/10543400701329422

16. Carstensen B, Simpson J, Gurrin LC. Statistical models for assessing agreement in method comparison studies with replicate measurements. Int J Biostat. (2008) 4:16. doi: 10.2202/1557-4679.1107

17. Critchley LA, Critchley JA. A meta-analysis of studies using bias and precision statistics to compare cardiac output measurement techniques. J Clin Monit Comput. (1999) 15:85-91.

18. Ebmeier SJ, Barker M, Bacon M, Beasley RC, Bellomo R, Knee Chong C, et al. A two centre observational study of simultaneous pulse oximetry and arterial oxygen saturation recordings in intensive care unit patients. Anaesth Intensive Care. (2018) 46:297-303. doi: 10.1177/0310057X1804 600307

19. Kohyama T, Moriyama K, Kanai R, Kotani M, Uzawa K, Satoh T, et al. Accuracy of pulse oximeters in detecting hypoxemia in patients with chronic thromboembolic pulmonary hypertension. PLoS ONE. (2015) 10:e0126979. doi: 10.1371/journal.pone.0126979

20. Pilcher J, Ploen L, McKinstry S, Bardsley G, Chien J, Howard L, et al. A multicentre prospective observational study comparing arterial blood gas values to those obtained by pulse oximeters used in adult patients attending Australian and New Zealand hospitals. BMC Pulm Med. (2020) 20:7. doi: 10.1186/s12890-019-1007-3

21. Montenij LJ, Buhre WF, Jansen JR, Kruitwagen CL, de Waal EE. Methodology of method comparison studies evaluating the validity of cardiac output monitors: a stepwise approach and checklist. Br J Anaesth. (2016) 116:7508. doi: 10.1093/bja/aew094

22. Odor PM, Bampoe S, Cecconi M. Cardiac output monitoring: validation studies-how results should be presented. Curr Anesthesiol Rep. (2017) 7:4105. doi: 10.1007/s40140-017-0239-0

23. Abu-Arafeh A, Jordan H, Drummond G. Reporting of method comparison studies: a review of advice, an assessment of current practice, and 
specific suggestions for future reports. Br J Anaesth. (2016) 117:56975. doi: $10.1093 / \mathrm{bja} /$ aew 320

24. Genecand L, Adler D, Beghetti M, Lador F. Cardiac output determination in precapillary pulmonary hypertension: a systematic review. Respir Int Rev Thor Dis. (2021) 1-8. doi: 10.1159/000517084

25. Hanneman SK. Design, analysis, and interpretation of methodcomparison studies. AACN Adv Crit Care. (2008) 19:22334. doi: 10.1097/01.AACN.0000318125.41512.a3

26. Cecconi M, Rhodes A, Poloniecki J, Della Rocca G, Grounds RM. Bench-tobedside review: the importance of the precision of the reference technique in method comparison studies-with specific reference to the measurement of cardiac output. Critical Care. (2009) 13:201. doi: 10.1186/cc7129

27. Waldron M, David Patterson S, Jeffries O. Inter-day reliability of finapres (®) cardiovascular measurements during rest and exercise. Sports Med Int Open. (2018) 2:E9-e15. doi: 10.1055/s-0043-122081

28. Shah N, Ragaswamy HB, Govindugari K, Estanol L. Performance of three new-generation pulse oximeters during motion and low perfusion in volunteers. J Clin Anesth. (2012) 24:38591. doi: 10.1016/j.jclinane.2011.10.012

29. Dupuis M, Noel-Savina E, Prévot G, Tétu L, Pillard F, Rivière D, et al. Determination of cardiac output in pulmonary hypertension using impedance cardiography. Respir Int Rev Thor Dis. (2018) 96:5006. doi: $10.1159 / 000486423$

30. Yung GL, Fedullo PF, Kinninger K, Johnson W, Channick RN. Comparison of impedance cardiography to direct Fick and thermodilution cardiac output determination in pulmonary arterial hypertension. Congest Heart Fail. (2004) 10:7-10. doi: 10.1111/j.1527-5299.2004.03406.x

31. KENDRICK AH WEST J, PAPOUCHADO M, ROZKOVEC A. Direct Fick cardiac output: Are assumed values of oxygen consumption acceptable? Eur Heart J. (1988) 9:337-42. doi: 10.1093/oxfordjournals.eurheartj.a062505

32. Fakler U, Pauli C, Hennig M, Sebening W, Hess J. Assumed oxygen consumption frequently results in large errors in the determination of cardiac output. J Thorac Cardiovasc Surg. (2005) 130:272-6. doi: 10.1016/j.jtcvs.2005.02.048

33. Wolf A, Pollman MJ, Trindade PT, Fowler MB, Alderman EL. Use of assumed versus measured oxygen consumption for the determination of cardiac output using the Fick principle. Cathet Cardiovasc Diagn. (1998) 43:372-80. doi: 10. 1002/(SICI)1097-0304(199804)43:4<372::AID-CCD3>3.0.CO;2-5

34. Kovacs G, Herve P, Barbera JA, Chaouat A, Chemla D, Condliffe $\mathrm{R}$, et al. An official European Respiratory Society statement: pulmonary haemodynamics during exercise. Eur Respir J. (2017) 50:1700578. doi: 10.1183/13993003.00578-2017

35. Fares WH, Blanchard SK, Stouffer GA, Chang PP, Rosamond WD, Ford HJ, et al. Thermodilution and Fick cardiac outputs differ: impact on pulmonary hypertension evaluation. Can Respir J. (2012) 19:2616. doi: $10.1155 / 2012 / 261793$

36. Khirfan G, Ahmed MK, Almaaitah S, Almoushref A, Agmy GM, Dweik RA, et al. Comparison of different methods to estimate cardiac index in pulmonary arterial hypertension. Circulation. (2019) 140:7057. doi: 10.1161/CIRCULATIONAHA.119.041614

37. Remmen JJ, Aengevaeren WR, Verheugt FW, van ver Werf T, Luijten HE, Bos A, et al. Finapres arterial pulse wave analysis with Modelflow is not a reliable non-invasive method for assessment of cardiac output. Clin Sci. (2002) 103:143-9. doi: 10.1042/cs1030143

38. Bogert LW, Wesseling KH, Schraa O, Van Lieshout EJ, de Mol BA, van Goudoever J, et al. Pulse contour cardiac output derived from non-invasive arterial pressure in cardiovascular disease. Anaesthesia. (2010) 65:111925. doi: $10.1111 / j .1365-2044.2010 .06511 . x$
39. Lador F, Hervé P, Bringard A, Günther S, Garcia G, Savale L, et al. Non-invasive determination of cardiac output in pre-capillary pulmonary hypertension. PLoS ONE. (2015) 10:e0134221. doi: 10.1371/journal.pone.0134221

40. Lipkin DP, Poole-Wilson PA. Measurement of cardiac output during exercise by the thermodilution and direct Fick techniques in patients with chronic congestive heart failure. Am J Cardiol. (1985) 56:3214. doi: 10.1016/0002-9149(85)90857-4

41. Hillis LD, Firth BG, Winniford MD. Analysis of factors affecting the variability of Fick versus indicator dilution measurements of cardiac output. Am J Cardiol. (1985) 56:764-8. doi: 10.1016/0002-9149(85)91132-4

42. Rich JD, Archer SL, Rich S. Noninvasive cardiac output measurements in patients with pulmonary hypertension. Eur Respir J. (2013) 42:12533. doi: $10.1183 / 09031936.00102212$

43. Dhingra VK, Fenwick JC, Walley KR, Chittock DR, Ronco JJ. Lack of agreement between thermodilution and fick cardiac output in critically ill patients. Chest. (2002) 122:990-7. doi: 10.1378/chest.122.3.990

44. Lador F, Bringard A, Bengueddache S, Ferretti G, Bendjelid K, Soccal PM, et al. Kinetics of cardiac output at the onset of exercise in precapillary pulmonary hypertension. Biomed Res Int. (2016) 2016:6050193. doi: 10.1155/2016/6050193

45. Hsu S, Brusca SB, Rhodes PS, Kolb TM, Mathai SC, Tedford RJ. Use of thermodilution cardiac output overestimates diagnoses of exercise-induced pulmonary hypertension. Pulm Circ. (2017) 7:253-5. doi: 10.1086/690629

46. Guo J, Shi X, Yang W, Gong S, Zhao Q, Wang L, et al. Exercise physiology and pulmonary hemodynamic abnormality in PH patients with exercise induced venous-to-systemic shunt. PLOS ONE. (2014) 10:e121690. doi: 10.1371/journal.pone.0121690

47. Reuter DA, Huang C, Edrich T, Shernan SK, Eltzschig HK. Cardiac output monitoring using indicator-dilution techniques: basics, limits, and perspectives. Anesth Analg. (2010) 110:799811. doi: 10.1213/ANE.0b013e3181cc885a

Conflict of Interest: None of the authors reports any conflict of interest in direct relation to this manuscript. SU reports grants from the Swiss National Science Foundation and Zurich Lung related to this work. She reports a grant from the Swiss Lung League, Janssen SA, Switzerland, Orpha Swiss, personal fees from Actelion SA, MSD, Orpha Swiss and Novartis, Switzerland, outside of the submitted work.

The remaining authors declare that the research was conducted in the absence of any commercial or financial relationships that could be construed as a potential conflict of interest.

Publisher's Note: All claims expressed in this article are solely those of the authors and do not necessarily represent those of their affiliated organizations, or those of the publisher, the editors and the reviewers. Any product that may be evaluated in this article, or claim that may be made by its manufacturer, is not guaranteed or endorsed by the publisher.

Copyright (๑) 2021 Duknic, Lichtblau, Saxer, Berlier, Schneider, Schwarz, Carta, Furian, Bloch and Ulrich. This is an open-access article distributed under the terms of the Creative Commons Attribution License (CC BY). The use, distribution or reproduction in other forums is permitted, provided the original author(s) and the copyright owner(s) are credited and that the original publication in this journal is cited, in accordance with accepted academic practice. No use, distribution or reproduction is permitted which does not comply with these terms. 